\title{
CHANNEL CATFISH ESTROGENICITY AND SEWER OVERFLOWS; IMPLICATIONS FOR XENOESTROGEN EXPOSURE
}

Conrad Daniel Volz, DrPH, MPH $\stackrel{1,2,3}{\underset{ }{2}}$, Frank Houghton, $\mathrm{PhD}^{4}$, Nancy Sussman, $\mathrm{PhD}^{2}$, Diana Lenzner, $\mathrm{MS}^{2}$, Devra Davis, PhD, $\mathrm{MPH}^{1,2}$, Maryann Donovan, $\mathrm{PhD}, \mathrm{MPH}^{1,5}$, Talal El Hefnawy, $\mathrm{PhD}, \mathrm{MD}^{1}$ and Patricia Eagon, $\mathrm{PhD}^{1,4,5}$

1. University of Pittsburgh Cancer Institute, Center for Environmental Oncology, Pittsburgh PA, USA. 2. University of Pittsburgh, Graduate School of Public Health, Pittsburgh PA, USA. 3. Scientific Director, Center for Healthy Environments and Communities, Pittsburgh, PA., USA. 4. Veterans Research Foundation, Veterans Affairs Medical Center, Pittsburgh PA USA. 5. School of Medicine, University of Pittsburgh, Pittsburgh PA, USA.

Abstract: Effluent from wastewater-treatment plants contains compounds that possess estrogenic activity. The southwestern Pennsylvania area has over 400 sewer overflows (SOs) that release untreated sewage. We sought to determine if the estrogenicity index (EI) of channel catfish from dense areas of SOs differed from catfish that are less impacted by SOs, using MCF-7 and BT-20 cell cultures. The MCF-7 human breast cancer line is estrogen receptor (ER) positive, while the BT-20 line is ER negative. The EI is based on the ratio of MCF-7 proliferation from application of fish extract to the response achieved from physiological levels of estradiol. Catfish caught near dense concentrations of SOs had significantly higher MCF-7 EIs than catfish from areas of less dense SOs, $(\mathrm{p}=0.02)$. The ER negative BT-20 cell line exhibited no proliferative response. We hypothesize that fish caught in concentrated areas of SOs have bioaccumulated more xenoestrogens than fish caught in less SO impacted areas. River water from SO contaminated areas is the primary source of drinking water for Allegheny County residents, potentially exposing large population groups to xenoestrogens. Our data suggest that evaluation of the estrogenicity of fish should be incorporated into risk assessment paradigms. Estrogen-screen evaluation of channel catfish is proposed as one model for further development.

\section{Background}

There is overwhelming evidence that effluents from sewage treatment plants exhibit strong human and animal in vitro and in vivo and in situ wildlife estrogenic activity (Aerni, 2004; Jobling et al, 2005; Liney et al., 2005; Petrovic et al., 2002). A wide variety of estrogenic agents is contained in municipal wastewater including pharmaceutical estrogens, phthalates, bisphenol-A, pesticides and detergent breakdown products like nonylphenol (Braga, 2005; Carbella et al., 2005; Carbella et al., 2004; Cargouet et al., 2004). Many xenoestrogens can bioaccumulate in aquatic systems because they are highly lipid soluble (Hemond, H. and E. Fechner-Levy. 2000).

The "Three Rivers" area of Pittsburgh has approximately 317, combined sewer overflows (CSOs) and sanitary sewer overflows (SSOs)--more than any other city in the United States, which release untreated municipal waste directly into receiving water during wet weather events (National Research Council, 2005). An estimated 16 billion gallons of sewage and stormwater are discharged yearly into receiving streams and main 
stem rivers in the Allegheny County Sanitary Authority (ALCOSAN) sewershed (Three Rivers Wet Weather, 2002).The main stem rivers affected by these CSOs and SSOs are the Allegheny and Monongahela Rivers and the river that they combine to form, the Ohio River, at Point State Park in downtown Pittsburgh. Rainfall amounts of as little as 1/10 inch can trigger opening of sewer outfall gates. Since CSOs and SSOs are released untreated, we hypothesized that they contain levels of pharmaceutical estrogens and xenoestrogens in excess of levels known to be released from wastewater treatment plants (WWTP) and further that channel catfish caught in areas of dense concentrations of CSOs and SSOs would display estrogenicity indexes that are higher than those caught in river areas that are less impacted by CSOs/SSOs.

\section{Objectives}

This study's objectives were:

1. To determine if the estrogenicity index of channel catfish fillet plus fat significantly varies by proximity to dense concentrations of CSOs and SSOs, as measured by the MCF-7 human breast cancer proliferative assay.

2. To determine if the channel catfish E-screen model can be used to help identify the sources of pharmaceutical estrogen and xenoestrogen pollution.

3. To involve semi-subsistence and recreational anglers in a Community Based Participatory Environmental Research Project.

4. To demonstrate to policymakers the known biological effects and potential environmental public health consequences of failure to update Allegheny County's and southwestern Pennsylvania's antiquated sewer systems.

\section{Materials and Methods}

We employed a community-based participatory environmental research approach (CBPR), working with community partners Venture Outdoors, Clean Water Action of Western Pennsylvania, fishing groups such as Bassmasters and individual anglers to understand common angling locations, fish taken and eaten by semi-subsistence and recreational fishers and to help determine sampling locations. All catfish were caught using rod and reel by local anglers as it has been demonstrated that scientists may catch smaller fish on average, which have bioaccumulated lower concentrations of contaminants, leading to potential underestimates of risk (Burger et al., 2006).

All CSOs and SSOs in the ALCOSAN service area were identified by latitude and longitude from a list provided in Appendix A and B of the US Department of Justice Consent Decree with ALCOSAN (USDOJ 2007). CSO/SSO locations in the Kittanning area were identified from Pennsylvania Department of Environmental Protection records. Geospatial plots of CSOs and SSOs were made with Arc View 9.1. CSO/SSO densities were calculated for channel catfish sampling locations on the Allegheny, Monongahela and Ohio rivers based on the number of CSOs/SSOs within a 1 mile radius, within the watershed of each sampling point, which includes their feeder streams. The number of CSOs/SSOs at various distances upstream of each sampling point was also calculated.

The MCF-7 human breast cancer cell line is alpha-estrogen receptor positive and provides a well-established reporter cell line to screen for estrogen and estrogen mimicking chemicals (Blom et al, 1998). MCF-7 is known to respond to estrogen stimuli by increasing DNA-synthesis in vitro. MCF-7 cells are frequently used to study cell 
proliferation by estrogens and estrogen mimicking substances (Mellanen et al. 1996; Soto et al. 1992; White et al. 1994). Cell proliferation assays (CPA) were performed under the direction of Patricia Eagon $\mathrm{PhD}$ at the University of Pittsburgh, School of Medicine. Briefly, a one gram section of the fish fillet and fat (taken at maximum body depth, from backbone to stomach) was homogenized with a chloroform-methanol solution $(80: 20, \mathrm{v} / \mathrm{v})$ to extract hormonally active substances. The chloroform methanol was evaporated with nitrogen, leaving a residue which was solubilized in ethanol-glycerol (3:1, v/v). A stock solution 1/100 fish extract was formed by combining $13.720 \mathrm{ml}$ of a steroid free medium (95\% RPI without phenol red and 5\% dextran-charcoal treated serum) and $2.8 \mathrm{ml}$ of 1/1 fish extract. MCF-7 and BT-20 cells were seeded at 5,000 cells per well. The experimental group wells were treated with the 1/100 dilution of fish extract, a $1 \mathrm{nM}$ solution of estradiol was added to estradiol positive controls, and negative controls received only steroid-free medium. After incubation and further treatment the absorbance of each well was then measured at $490 \mathrm{~nm}$ with a Bio-Tek Synergy HT well plate reader. The 490nm absorbance is directly proportional to the number of living cells in culture.

The presented estrogenicity index is based on the ratio of the MCF-7 cell proliferation achieved from application of fish extract to the mean proliferative response of the estradiol (E2) controls. The mean estrogenicity index of fishes from areas of densehigh CSO/SSO $(n=10)$ were compared with those from low CSO/SSO density areas $(\mathrm{n}=9)$ using ANOVA with SPSS Version 12.0.

\section{Results and Discussion}

Figure 1, Arc GIS Map of Combined and Sanitary Sewer Overflows in the ALCOSAN Study Area, presents all CSO/SSO locations on the Monongahela, Allegheny and Ohio Rivers and on their feeder streams as well as catfish sampling locations. The map outlines all watersheds within Allegheny County, which includes the City of Pittsburgh; 69\% of the urbanized population (approximately 1,282,000 people) of the 10 county Southwestern Pennsylvania area lives in Allegheny County (Southwestern Pennsylvania Commission, 2007). Table 1 Sampling Locations, CSO/SSO Densities and Estrogenicity Data presents the locations of channel catfish catch, river of catch, number of CSOs/SSOs within a 1 mile radius (within watershed) of the sampling location, number of CSOs/SSOs within 1 mile upstream from the sampling location, number of samples and the mean, maximum, minimum and standard deviation of the estrogenicity index (EI) for channel catfish caught by location.

The 1-mile radius density of CSO/SSO outfalls was greatest at Point State Park (PSP) and at the Braddock Dam on the Monongahela River. CSO/SSO outfall density significantly decreased near the Highland Park Dam in Sharpsburg and even more so near Kittanning PA, both on the Allegheny River. The sampling locations at PSP and at the Braddock Dam on the Monongahela River each have a total of 53 CSO/SSO outfalls within a 1 mile radius of the sampling site, within its watershed. As you move upstream on the Allegheny River from PSP there are $72 \mathrm{CSO} / \mathrm{SSO}$ outfalls in the 7 miles between PSP and the Highland Park Dam. Upstream from PSP on the Monongahela River there are 62 CSO/SSO outfalls in the 11 miles between PSP and the Braddock Dam. CSO/SSO density falls near the Highland Park Dam sampling site as there are 17 CSO/SSO outfalls within a 1 mile radius of the site; of these only 4 CSOs and 2 SSOs are within the ALCOSAN system upstream from this site. There are only 3 identified CSO sites within 
3 miles of the Kittanning sampling site, located approximately 40 miles upstream of PSP, on the Allegheny River.

Figure 1, Arc GIS Map of Combined and Sanitary Sewer Overflows in the ALCOSAN Study Area

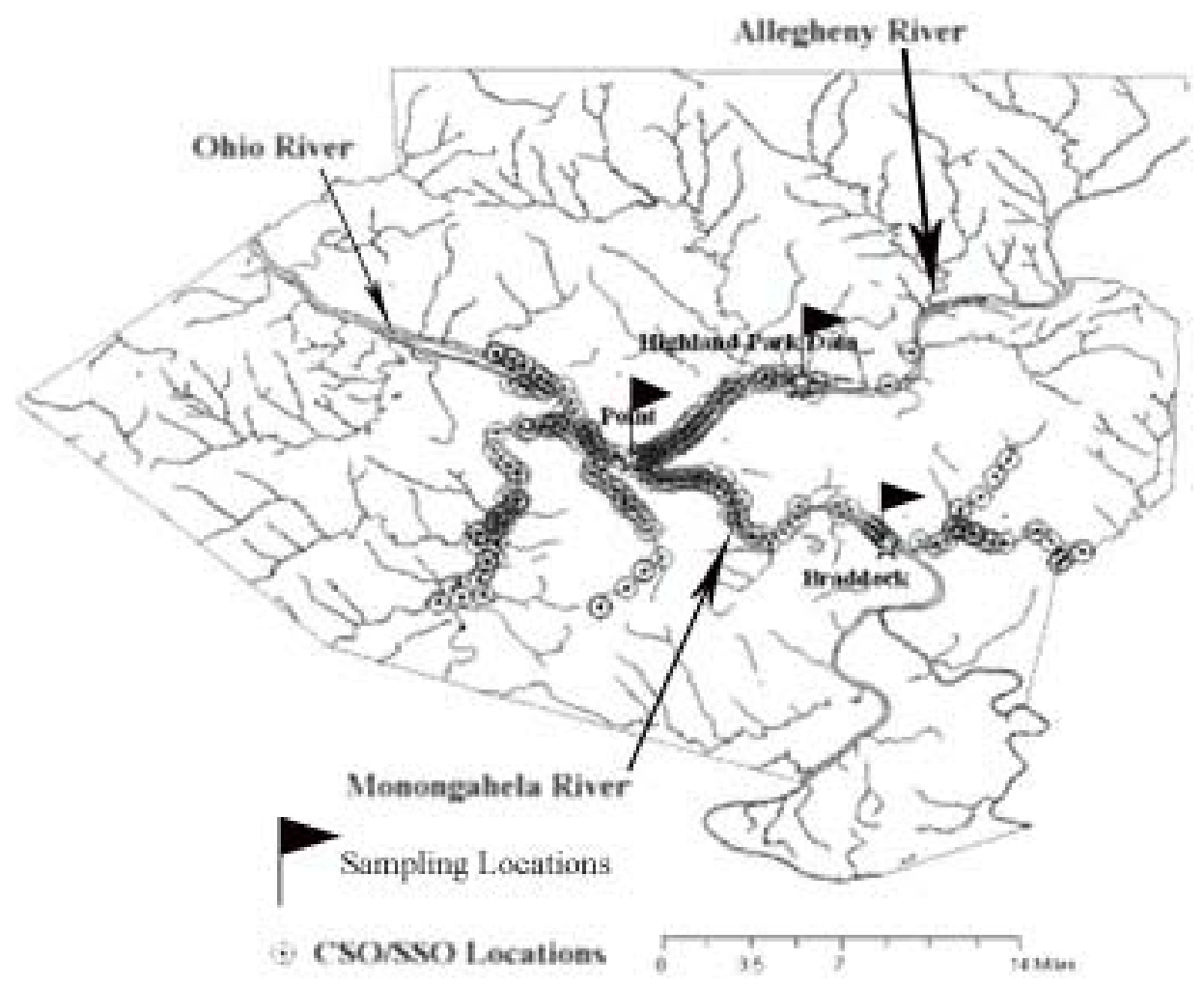

Table 1, Sampling Locations, CSO/SSO Densities and Estrogenicity Data

\begin{tabular}{|l|l|l|l|l|}
\hline Sampling Location & Point State Park & Braddock Dam & $\begin{array}{l}\text { Highland Park } \\
\text { Dam }\end{array}$ & Kittanning Dam \\
\hline River & $\begin{array}{l}\text { Allegheny/ } \\
\text { Monongahela } \\
\text { Confluence, Ohio }\end{array}$ & Monongahela & Allegheny & Allegheny \\
\hline $\begin{array}{l}\text { CSOs/SSOs Radius } \\
\text { of 1 Mile }\end{array}$ & $\mathbf{5 3}$ & $\mathbf{5 3}$ & 17 & $3^{*}$ \\
\hline $\begin{array}{l}\text { CSOs/SSOs 1 mile } \\
\text { upstream }\end{array}$ & 32 & 22 & 6 & 1 \\
\hline Number of Samples & 4 & 6 & 3 & 6 \\
\hline $\begin{array}{l}\text { Mean Estrogenicity } \\
\text { Index, } \\
\text { Dilution } 1 / 100\end{array}$ & $\mathbf{0 . 5 4}$ & $\mathbf{0 . 4 0}$ & 0.23 & 0.31 \\
\hline $\begin{array}{l}\text { Min } \\
\text { EI }\end{array}$ & 0.31 & 0.17 & 0.13 & 0.20 \\
\hline Max EI & $\mathbf{0 . 6 7}$ & $\mathbf{0 . 6 7}$ & 0.34 & 0.44 \\
\hline Std. Dev. EI & 0.15 & 0.19 & 0.11 & 0.11 \\
\hline
\end{tabular}

* within a radius of 3 miles. 
ANOVA revealed that catfish caught at locations of dense concentrations of CSO outfalls (Point State Park and Braddock Dam) had significantly higher MCF-7 estrogenicity indexes than catfish from areas of less dense CSO effluents (Highland Park Dam and Kittanning Dam). This relationship was significant at $p=0.02$. Catfish extract and estradiol application produced no proliferation of the BT-20 estrogen receptor negative cell line, suggesting that the fish extracts contain no non-estrogenic proliferation enhancers.

\section{Conclusions}

We hypothesize that extracts from fish caught in the densely concentrated areas of CSOs/SSOs are more estrogenic because they have bioaccumulated more pharmaceutical estrogens and xenoestrogens than fish caught in less CSO impacted areas. While the specific estrogenic compounds in the fish extracts are not yet identified; there is a growing literature indicating that a wide range of household and personal care products, pharmaceuticals, and lawn and garden pesticides with estrogenic potential are being emitted from waste water treatment plants and are contained in raw sewage emitted from CSOs and SSOs during wet weather events.

The environmental public health significance of this work is considerable: the source water for most of the population of the Greater Pittsburgh Metropolitan area is surface water from the Allegheny, Monongahela and Ohio Rivers. In fact the West View Water Authority source water intake pipes, serving over 200,000 people, in 31 municipalities, in portions of Allegheny, Beaver, and Butler Counties (West View Water Authority, 2007), are located just downstream from the ALCOSAN WWTP release point and have approximately $180 \mathrm{CSOs/SSOs}$ within a 5 mile radius of these water intake pipes. There is increasing evidence that endocrine disrupting chemicals can affect human populations. Populations that consume fish from areas high in xenoestrogens are at higher risk for developing cancer, neurological impairment, and reproductive problems (Colborn 1993). Testicular cancer and other male reproductive problems are increasing and may be attributed to endocrine disruptors in the environment as well (Davis et al., 2007; Toppari et al., 1996; Adami et al., 1994). Other studies show that over the past 50 years there has been a steady decline in human sperm count which could be attributed to estrogenic effects (Carlsen 1992; Auger 1995; VanWaeleghem 1996). Additional studies have shown that endocrine disrupting chemicals are linked to developmental deficiencies and learning disabilities in children (EPA, 2001). Currently neither WWTPs nor water finishing plants are required to either sample for or treat source water for pharmaceutical estrogens and xenoestrogens

Naturalistic wildlife and holistic ecosystem studies provide valuable risk information concerning cumulative estrogenicity at the level of a system or population. An important aspect of the total risk to humans and the environment from ingestion of xenoestrogens is the profusion of substances with estrogenic activity that are being introduced into water through municipal (household) sources. The EPA must incorporate appropriate methodologies to evaluate total estrogenic risk from environmental mixtures of common xenoestrogens. E-screen evaluation of the channel catfish is proposed as one model for further discussion and development. 


\section{Acknowledgements}

The authors express their appreciation to the DSF Charitable Trust, the Heinz Endowments and Highmark Foundation, and University of Pittsburgh Cancer Institute (UPCI) for funding this research through the Center for Environmental Oncology of UPCI. CDV and DD are also funded through the Centers for Disease Control and Prevention's Environmental Public Health Tracking (EPHT) Program through a grant to the University of Pittsburgh, Academic Center of Excellence in EPHT. Many thanks go to Joanna Burger, $\mathrm{PhD}$ and Michael Gochfeld, $\mathrm{MD}, \mathrm{PhD}$ for impressing upon CDV the importance of ecological receptors as biomonitors in exposure assessment studies.

\section{Correspondence}

Conrad Volz, DrPH, MPH cdv5@pitt.edu, 724-316-5408, Department of Environmental and Occupational Health, Graduate School of Public Health, University of Pittsburgh, Bridgeside Point, 100 Technology Drive, Suite 564, BRIDG, Pittsburgh, PA 15219-3130

\section{References}

Adami, B., Mohner (1994).Testicular cancer in nine northern European countries. International Journal of Cancer 59: 33-38.

Aerni, H. R., Kobler, B., Rutishauser, B. V., Wettstein, F. E., Fischer, R., Giger, W., Hungerbuhler, A., Marazuela, M. D., Peter, A., Schonenberger, R., Vogeli, A. C., Suter, M. J. F., Eggen, R. I. L., 2004.Combined biological and chemical assessment of estrogenic activities in wastewater treatment plant effluents. (Special issue: endocrine disruptors). Analytical and Bioanalytical Chemistry. Springer-Verlag, Berlin, Germany: 2004. 378: 3, 688-696.

Auger, J. (1995). "Decline in semen quality among fertile men in Paris during the past 20 years." New England Journal of Medicine(332): 281-285.

Burger, J., Gochfeld M , Burke S, Jeitner C, Jewett S, Snigaroff D, Snigaroff R, Stamm T, Harper S, Hoberg M, Chenelot H, Patrick R, Volz CD, Weston J, 2006. "Do scientists and fishermen collect the same size fish? Possible implications for exposure assessment." Environmental Research 101(1): 34-41.

Blom A, Ekman E, Johannisson A, Norrgren L, Pesonen M, 1998. Effects of Xenoestrogenic environmental pollutants on the proliferation of a human breast cancer cell line (MCF-7). Achieves of. Environmental. Contamination and Toxicology 34, 306310.

Braga, O., G. A. Smythe, et al., 2005. Steroid estrogens in primary and tertiary wastewater treatment plants. Water Science \& Technology 52(8): 273-8.

Cargouet, M., D. Perdiz, , Mouatassim-Souali D., Tamisier-Karolak A., Levi S., 2004.Assessment of river contamination by estrogenic compounds in Paris area (France). Science of The Total Environment 324(1-3): 55-66. 
Carballa, M., F. Omil, et al., 2005. Behaviour of pharmaceuticals and personal care products in a sewage treatment plant of northwest Spain. Water Science and Technology. IWA Publishing, London, UK: 2005. 52: 8, 29-35.

Carballa, M., F. Omil, et al., 2004. Behavior of pharmaceuticals, cosmetics and hormones in a sewage treatment plant. Water Research (Oxford). Elsevier, Oxford, UK: 2004. 38: 12, 2918-2926.

Carlsen, 1992. Evidence for decreasing quality of semen during the past 50 years. British Medical Journal (305): 609-613.

Colborn, V. S., and Soto, 1993. Developmental effects of endocrine-disrupting chemicals in wildlife and humans. Environmental Health Perspectives 101(5): 378-384.

Davis, D., Webster, P., Stainthorpe, H, Chilton, J., Jones, L., Doi, R., 2007. Declines in sex ratio at birth and fetal deaths in Japan, and in U.S. Whites but not African Americans, Environmental Health Perspectives 115(6):941-6.

EPA, 2001. Removal of endocrine disruptor chemicals using drinking water treatment processes. Washington, DC, Office of Research and Development.

Hemond, H. and E. Fechner-Levy. 2000. Chemical Fate and Transport in the Environment. 2nd ed. San Diego: Academic Press.

Jobling, S., R. Williams, et al., 2006. Predicted exposures to steroid estrogens in U.K. rivers correlate with widespread sexual disruption in wild fish populations. Environmental Health Perspectives 114 Suppl. 1: 32-9.

Liney, K. E., Hagger, J. A., et al., 2006. Health effects in fish of long-term exposure to effluents from wastewater treatment works. Environmental Health Perspectives 114 Suppl 1: 81-9.

Mellanen P, Petänen T, Lethimáki J, Mákela“ S, Bylund G, Holmbom B, Mannila E, Oikari A, Santti R, 1996. Wood-derived estrogens: studies in vitro with breast cancer cell lines and in vivo in trout. Toxicology and Applied Pharmacology 136:381-388.

National Research Council, 2005. Regional Cooperation for Water Quality Improvement in Southwestern Pennsylvania. Washington, D.C.: National Academies Press.

Petrovic, M., Sole’, M., Lopez, de Alda, M., Barcelo, D., 2002. Endocrine disruptors in sewage treatment plants, receiving river waters, and sediments: integration of chemical analysis and biological effects on feral carp. Environmental Toxicology and Chemistry;21(10):2146-56. 
Soto AM, Lin T-M, Justicia H, Silvia RM, Sonnenschein, C, 1992. An "in culture" bioassay to assess the estrogenicity of xenobiotics (E-screen). In: Colborn T, Clement C (eds) Chemically-induced alterations in sexual and functional development: the wildlife/ human connection. Princeton Scientific Publishing Co, NJ, pp 295-309.

Southwestern Pennsylvania Commission, accessed September 4, 2007 http://www.spcregion.org/pdf/datalib/units.xls :original United States Census 2000 Summary File 1 Supplement released June 2003; data are municipal summation of census block data.

Toppari J, Larsen JC, Christiansen P, Giwercman A, Grandjean P, Guillette LJ Jr, Jégou B, Jensen TK, Jouannet P, Keiding N, Leffers H, McLachlan JA, Meyer O, Müller J, Rajpert-De Meyts E, Scheike T, Sharpe R, Sumpter J, Skakkebaek NE., 1996. Environmental Health Perspectives;104 Suppl 4:741-803.

Three Rivers Wet Weather, 2002. THE REGIONALIZATION REPORT:

An initial study on options for regionalizing the management of sewage collection within the ALCOSAN service area. 3 Rivers Wet Weather Demonstration Program, 3901 Penn Avenue, Building \#3, Pittsburgh, PA 15224.

http://www.3riverswetweather.org/f_resources/regionalization_report.pdf 8/26/07.

United States Department of Justice, 2007, Consent Decree between United States of America, Commonwealth of Pennsylvania, Department of Environmental Protection, and Allegheny County Health Department vs. Allegheny County Sanitary Authority, Appendices A\&B http://www.alcosan.com/Consent\%20Decree/Alcosan\%20\%20Consent\%20Decree\%20for\%20Signatures.pdf , accessed August 15, 2007.

VanWaeleghem (1996). "Deterioration of sperm quality in healthy Belgium men." Human Reproduction(11): 325-329.

West View Water Authority, 2007. http://www.westviewwater.org accessed 8/30/07.

White R, Jobling S, Hoare SA, Sumpter JP, Parker MG, 1994. Environmentally persistent alkylphenolic compounds are estrogenic. Endocrinology 135(1):175-182. 